\title{
Subsídios para a diversificação de moradias destinadas a pessoas com transtorno mental grave no Brasil: uma revisão*
}

\author{
Juarez Pereira Furtado ${ }^{1}$
}

FURTADO, J.P. Support for diversification of housing for people with severe mental disorders in Brazil: a review. Interface (Botucatu), v.17, n.46, p.635-47, jul./set. 2013.

Because of criticism of so-called mental hospitals, a variety of housing initiatives for people being discharged from psychiatric hospitals have needed to be implemented in different countries. In this paper, from a narrative review, we analyzed the background to and establishment of homes for people with severe mental disorders implemented in Brazil, through the Brazilian National Health System. We found that there had been little discussion about the limits of the residential therapeutic service program, and almost no discussion about alternatives for the housing needs of severely ill patients connected with psychosocial care centers. With support from reflections derived from Canadian experience, we discuss the need for and possible ways of expanding the forms of support for housing for people with severe mental disorders in Brazil, not only quantitatively, but also qualitatively.

Keywords: Public health. Program evaluation. Mental health. Assisted living facilities.
Com as críticas ao chamado manicômio, diversas iniciativas de moradia para egressos de hospitais psiquiátricos precisaram ser implementadas em diferentes países. Neste artigo, a partir de revisão narrativa, analisamos os antecedentes e a constituição de moradias para pessoas com transtorno mental grave implementadas no Brasil, pelo Sistema Único de Saúde. Identificamos pouca discussão sobre os limites do programa de Serviços Residenciais Terapêuticos (SRTs) e a quase inexistência de discussões sobre alternativas para as necessidades de moradia de pacientes graves ligados aos Centros de Atenção Psicossocial (Caps). Subsidiados por reflexões oriundas da experiência canadense, discutimos a necessidade e os caminhos possíveis de ampliação não só quantitativa, mas, sobretudo, qualitativa, das formas de apoio às moradias de pessoas com transtorno mental grave no Brasil.

Palavras-chave: Saúde Pública. Avaliação de programas e projetos de saúde. Saúde mental. Moradias assistidas.

\footnotetext{
"Texto elaborado em contexto de pesquisa financiada pelo Conselho Nacional de Pesquisa, CNPq (Edital $33 / 2008$, processo 575150/2008-4).

${ }^{1}$ Departamento Políticas Públicas e Saúde Coletiva, Instituto Saúde e Sociedade, Universidade Federal de São Paulo (Unifesp), campus Baixada Santista. R. Silva Jardim, 136, VI. Mathias. Santos, SP, Brasil. 11015-020. juarezpfurtado@ hotmail.com
} 
Eu e a casa sofremos de uma mesma doença: saudades.

(Couto, 2012, p.3)

\section{O problema}

Urge desospitalizar os milhares de moradores de hospitais psiquiátricos brasileiros e, também, garantir, para outros milhares de pessoas com transtorno mental grave (TMG), acompanhados pelos Caps, suporte às suas necessidades de moradia, garantindo, para essa clientela, o direito de efetivamente continuar inserida no espaço urbano e social de nossas cidades. A discussão da necessidade dessa simultânea ampliação (dos SRTs) e diversificação (para novas clientelas) do suporte às moradias de pessoas com TMG constitui o tema deste estudo.

No local de morada convergem muitos e importantes aspectos da constituição do indivíduo, podendo-se encontrar ali respostas, abrigo e contorno para aspectos que vão do mais íntimo e individual ao coletivo e relacional (Morin, Robert, Dorvil, 2001), representando importante determinante social da saúde mental e elemento decisivo na inserção e manutenção de pessoas em meio social e comunitário (Beaulieu, Dorvil, 2004). Acumulam-se importantes estudos, em distintas localidades, reiterando o papel decisivo do equacionamento das necessidades de moradia para pessoas com transtorno mental grave (TMG). Para Tsemberis (2004), o acesso e a permanência em moradias são considerados fatores fundamentais na integração de doentes mentais, sobretudo em grandes meios urbanos, como Nova York. A partir de sua experiência (Tsemberis, 2004), o autor defende modelos de habitação plenamente integrados na comunidade e, mais que flexíveis, transigentes com as muitas questões que atravessam a psicose e o uso abusivo de drogas. No Brasil, há publicação cujo conjunto de artigos discute e/ou apresenta relatos de experiências de êxito na implementação e no acompanhamento de egressos de longas internações psiquiátricas em residências a eles destinadas, salientando a importância das novas moradias para os egressos de longas internações psiquiátricas (Cadernos IPUB, 2006).

Estudos de outra natureza - sistemáticos e prospectivos - também têm apontado resultados positivos de moradias no âmbito da desinstitucionalização psiquiátrica. Trieman et al. (1999), acompanhando prospectivamente, por cinco anos, seiscentos e setenta pacientes oriundos de dois hospitais psiquiátricos de Londres, analisaram fatores como: qualidade de moradia, frequência de reinternações em urgências e hospitais psiquiátricos, e situações de desabrigo (homeless), concluindo que - se bem planejados e estruturados - os cuidados às pessoas com TMG em casas inseridas na comunidade são benéficos às mesmas e não trazem riscos para os demais segmentos da sociedade.

Ao mesmo tempo, elemento físico e relacional de grande importância para toda e qualquer pessoa, o local e as condições de moradia assumirão particular importância para a pessoa em sofrimento mental grave, em vista dos contornos que a casa pode oferecer e da referência em que pode vir a se constituir. Para a pessoa com TMG, o lar pode oferecer espaço de necessária complacência a eventuais sintomas e constituir ponto de partida para aspectos que ultrapassam o morar, mas que dele dependem, como a rede social e a inserção em atividades de trabalho (Dorvil, 2004). Considerações compartilhadas por Saraceno (1999), para quem a moradia forma, junto com a rede social e o trabalho, a tríade fundamental no processo de reabilitação e inserção social. Para Saraceno (1999), a noção de moradia inclui não só a estrutura física, mas, também, as diferentes maneiras de apropriação do espaço e dos modos de habitá-lo.

No entanto, iniciativas desenvolvidas nas últimas décadas no Brasil, voltadas para o suporte e apoio às necessidades de moradia de pessoas com transtorno mental grave, têm ficado restritas aos chamados Serviços Residenciais Terapêuticos. Nosso pressuposto é de que urge refletir e buscar novos modos de prover e apoiar moradias de pessoas com transtorno mental grave, de modo a garantir sua efetiva permanência na comunidade.

Para isso, realizamos revisão narrativa sobre o tema (Pereira, 2011), utilizando a expressão "Serviços Residenciais Terapêuticos" como palavra-chave na base Scientific Eletronic Library On Line (Scielo) e na chamada literatura cinzenta, composta de textos não indexados ou não publicados. A partir daí, pudemos: reconstituir alguns antecedentes importantes do que atualmente compreendemos como 
moradias para pessoas com doenças mentais; identificar as principais questões que se constituíram objeto nas publicações mais recentes, e discutir saídas à atual iniciativa voltada para equacionar moradia para pessoas com TMG, oferecendo subsídios para a diversificação qualitativa de opções de moradia, de modo a superar os SRTs como alternativa única.

\section{Alguns predecessores: Geel, Juliano Moreira e Franco da Rocha}

Geel, cidade ao norte da Bélgica, constitui referência obrigatória quando se trata de inventariar o convívio de doentes mentais na comunidade e as diferentes formas de moradia a eles destinadas. Dimphna, jovem degolada aos 18 anos, por recusar casar-se com o próprio pai, um rei celta, foi canonizada pela Igreja católica em 1247, santa e padroeira do que hoje compreendemos como doentes mentais, com base nas curas milagrosas obtidas a partir de relíquias encontradas no local de seu martírio, um oratório em uma floresta em Flandres. Uma legião de pessoas com sofrimento mental peregrinaram, em busca de cura, até a floresta e a pequena capela onde, próximo a Geel, Dimphna foi morta.

A crença de que eram necessários nove dias (novena) de permanência na igreja de Santa Dimphna para obtenção da cura, somada ao grande afluxo de pessoas, levou os habitantes locais a receberem os peregrinos em suas próprias casas ou a criarem espaços a eles destinados, em um misto de pragmatismo e solidariedade, constituindo a experiência dessa pequena cidade (hoje belga) o que contemporaneamente identificaríamos como um movimento de convívio social e de provimento de moradias em espaço comunitário para os doentes mentais (Leduc, 1987).

O que torna a experiência de Geel particularmente importante é sua duração, uma vez que o peculiar convívio e coabitação entre comunidade e pessoas com TMG atravessou os séculos, chegando aos dias atuais. Ainda que o número de pensionistas esteja em declínio - aproximadamente quinhentos pensionistas em famílias de acolhimento (Goldstein, Godemont, 2003) - a pequena cidade tem servido de referência para profissionais de outros países interessados na desinstitucionalização psiquiátrica, seja por causa das referidas moradias ou por outras iniciativas de atenção e inserção na comunidade (Leduc, 1987).

No início do século XX, a experiência de Geel influenciará Juliano Moreira na constituição do modelo assistencial de sua Colônia para psicopatas-homens, sobretudo no que diz respeito à proposta de assistência heterofamiliar, na década de 1910. Nas palavras do próprio Juliano Moreira,

[...] deve o governo construir casinhas higiênicas para alugar às famílias dos bons empregados que poderão receber pacientes susceptíveis de serem tratados em domicílio. Far-se-há assim assistência familiar. Se nas redondezas da colônia houver gente idônea a quem confiar alguns doentes, poder-se-há ir estendendo essa assistência hetero-familiar e até tentar a homo-familiar. (Moreira 1910, apud Venâncio, 2011, p.38)

Também no início do século XX, Franco da Rocha, em São Paulo, irá propor a assistência familiar como estratégia para dar vazão aos doentes crônicos, cuja desocupação dos leitos hospitalares permitiria absorver o crescente número de doentes novos provenientes de várias regiões do estado e do país. Nesse momento, então, a ideia de transferência para casas de família prende-se à necessidade de racionalizar os custos gerados pelos pacientes, não estando em questão, propriamente, o hospital psiquiátrico. Segundo Juliano Moreira, nos Archivos Brasileiros de Psychiatria, Neurologia e Sciencias Afins, referindo-se ao êxito alcançado por seu colega Franco da Rocha, em São Paulo, com a assistência familiar:

Convido pensar no futuro quando o aumento de doentes fôr tal que comece a ser por demais oneroso ao Estado, terão os poderes publicos de recorrer á assistencia familiar dos insanos susceptiveis della. E então, dadas as nossas condições sociaes, sómente nas proximidades de uma colonia agrícola, já a esse tempo muito bem organizada, será possível effectuar aquele progresso. Tenho enorme satisfação em verificar que o espirito clarividente 
de Franco da Rocha vae demonstrar por meio de uma convincente experiencia que mesmo no Brasil é exequivel a assistencia familiar a alienados. (Moreira, 1906, p.3)

As famílias de acolhimento ou nutrícios, como eram chamados os responsáveis, foram compostas de camponeses pobres e, mais tarde, de pessoal do próprio hospital. Tais pessoas serão responsáveis por alimentação, vestuário e saúde geral dos internos, sendo esses últimos todos do sexo masculino e, preferencialmente, com capacidade de realizar algum tipo de trabalho (Urquiza, 1991).

As iniciativas de inserção de internos em casas de família, desencadeadas por Juliano Moreira e Franco da Rocha, serão pontuais e inseridas no modelo centrado nos grandes asilos surgido no Brasil do século XIX (Oda, 2005), configurando-se como complemento, e não alternativa ou crítica ao modelo de assistência em implantação por eles no Brasil. Ainda assim, podem ser consideradas as primeiras experiências em solo pátrio destinadas à retirada de pacientes cronificados do interior dos hospitais e sua inserção em casas na comunidade, prevendo-se, inclusive, algum acompanhamento e/ou supervisão pela instituição de origem.

Somente décadas mais tarde, nos primórdios de discussões críticas e questionamento do modelo hospitalar hegemônico em saúde mental, teremos proposições e/ou iniciativas de inserção de egressos de longas internações não mais em casas de família, mas em moradias compostas exclusivamente de pacientes, preconizadas por órgãos federais (Brasil, 1973), e efetivamente desenvolvidas, nos anos 1980, na própria instituição fundada por Franco da Rocha (Palladini, 1987).

É na década de 1990 que podemos identificar experiências pioneiras que influenciaram diretamente e ajudaram a conformar uma alternativa concreta de saída para os pacientes internados por longos períodos em hospitais psiquiátricos. Tais iniciativas surgiram não mais para o aperfeiçoamento do modelo centrado nos hospitais psiquiátricos. Pelo contrário, surgiram no contexto de radical mudança da assistência em saúde mental proposta pela reforma psiquiátrica - caracterizada por um novo paradigma voltado ao estabelecimento de nova relação da sociedade com os chamados loucos, à superação do modelo hospitalar, à oferta de serviços na comunidade e à reinserção social de portadores de TMG (Amarante, 2001).

Nas cidades de Porto Alegre, Ribeirão Preto (Guimarães, Saeki, 2001) e Campinas (Braga Campos, Guarido, 2006; Furtado, Pacheco, 1998), desenvolveram-se iniciativas de inserção de pessoas com TMG, moradores de asilos psiquiátricos, em espaços residenciais. Em que pesem as diferenças existentes entre essas experiências, provenientes dos distintos contextos, era explícita a intenção de superar o isolamento e, sobretudo, implementar alternativas de moradia para aqueles não mais aceitos pela família ou cujos laços familiares se perderam. Tais experiências foram precursoras diretas do que, a partir da portaria 106/2000 do Ministério da Saúde, passou a ser chamado de Serviços Residenciais Terapêuticos (SRTs).

\section{A política brasileira de moradias para pessoas com transtorno mental grave}

As portarias 106/2000 e 1.220/2000 do Ministério da Saúde (Brasil, 2002) oficializaram os SRTs no SUS, estabelecendo sua estrutura básica, modo de operar e financiamento. A partir daí, as pensões protegidas, lares abrigados, vilas terapêuticas, moradias extra-hospitalares e núcleos de convívio - como até então eram chamadas as diversas experiências pioneiras já citadas, destinadas aos egressos de longa internação (Suiyama, Rolin, Colvero, 2007) - passam a ser chamadas de Serviços Residenciais Terapêuticos. Tal nomenclatura foi questionada à época, sobretudo no que concerne aos termos "serviços" e "terapêuticos", inseridos justamente para justificar e viabilizar sua inserção no SUS.

Notemos aí que, ao menos em tese, considerou-se a possibilidade de que tais moradias pudessem ser abrigadas em outros setores, como o de promoção e assistência social. Contudo, a assistência social no Brasil dos anos 1990 deparava-se com a grande tarefa de superar o clientelismo, o paternalismo e a filantropia que lhe eram quase inerentes. A impossibilidade do setor de assistência social para abrigar a iniciativa dos SRTs foi propulsora, no interior da Reforma Psiquiátrica, da ampliação do campo dessa 
última. Assumindo aspectos relativos à moradia dos egressos, em seus mais diversos componentes, a área da saúde mental amplia seus aspectos interdisciplinar e intersetorial.

Os SRTs foram concebidos e destinados à população de pacientes moradores em hospitais psiquiátricos públicos e privados (conveniados com o Sistema Único de Saúde) do Brasil. Trata-se de casas inseridas preferencialmente no espaço urbano, destinadas a receber entre um e oito egressos, que deverão ter o suporte clínico e de reabilitação psicossocial garantido pela rede municipal de saúde mental. O financiamento dos SRTs é oriundo dos recursos que até então mantinham os egressos em seus respectivos hospitais - a conhecida guia de autorização de internação hospitalar (AIH). Ou seja, a normatização do Ministério da Saúde prevê que o antigo leito ocupado pelo egresso seja extinto e o recurso a ele atrelado (por meio das AlHs) seja destinado ao município. Desse modo, a cada saída de um paciente morador de hospital em direção ao SRT, extingue-se um leito hospitalar e o recurso vai para a secretaria municipal de saúde que implementou o SRT (de certa forma, podemos entender essa mudança como a substituição de financiamento de "leitos" por "camas").

A partir desses contornos mais gerais de financiamento e estruturação física, cada município estabelece suas próprias características: modelo de assistência e acompanhamento aos residentes, tipo e quantidade de profissionais envolvidos, estabelecimento ou não de convênio com ONGs para responder à flexibilidade requerida na gestão do cotidiano das casas, dentre outras.

No entanto, o programa de SRTs, única iniciativa oficial voltada para as questões de moradia de pessoas com TMG, tem beirado a estagnação, mantendo-se, há alguns anos, em restrita expansão (vide Gráfico 1), por razões não totalmente conhecidas e que tentamos identificar em estudo anterior (Furtado, 2006).

Dados do Ministério da Saúde, apresentados no II Encontro Nacional de SRTs, em abril de 2010, na cidade de Porto Alegre, demonstram que o número de dois mil e quinhentos moradores nessas casas é tímido se considerados os seis mil e quinhentos moradores potenciais no estado de São Paulo (Barros, Bichaff, 2008) ou os 12 mil representados por "moradores de hospital" ainda internados na totalidade dos estados brasileiros (vide Gráfico 2), situação existente apesar de quase vinte anos de experiência se considerarmos as iniciativas pioneiras citadas - e do fomento existente à expansão dos SRTs a partir da portaria 106/2000.

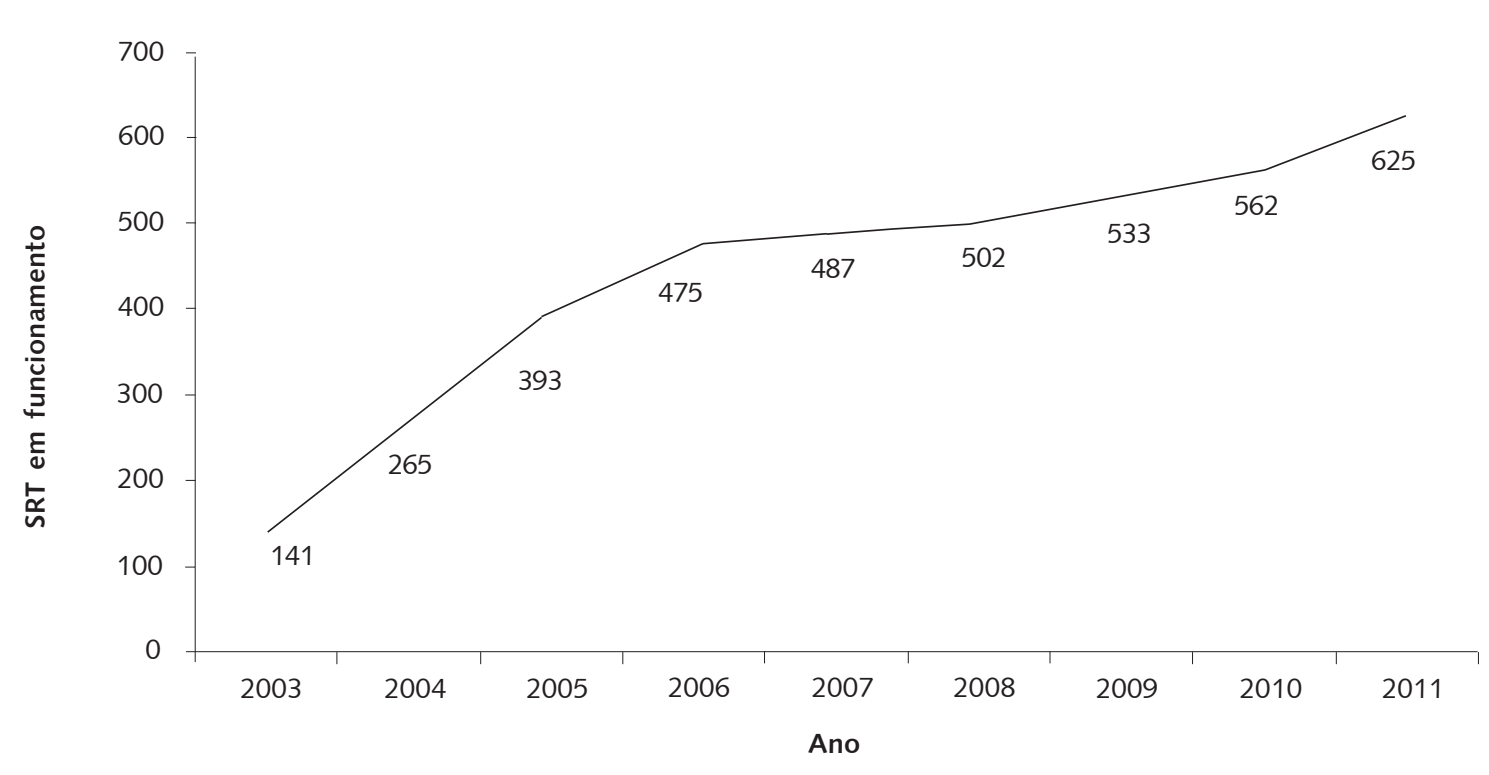

Gráfico 1. SRTs em funcionamento no Brasil 


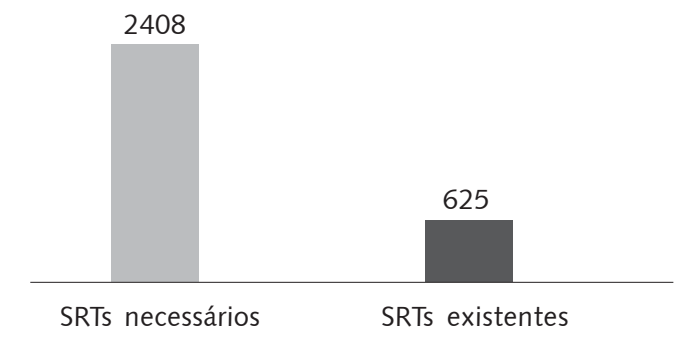

Gráfico 2. Número de SRTs necessários para a clientela moradora de hospitais psiquiátricos no Brasil

À atual paralisação na expansão de novas unidades destinadas a retirar internos de longa data em leitos psiquiátricos, vem somar-se a inexistência de programas e iniciativas estatais sistemáticas voltadas para pessoas sem histórico de longas internações psiquiátricas, estabelecendo um gargalo no acesso e garantia de moradia para essa clientela. Ambas as questões evidenciam dificuldades de nossa sociedade no enfrentamento da questão e na garantia de alternativas a um direito humano fundamental - o de moradia - e no estabelecimento, a contento, de alternativas a uma das funções latentes dos hospitais psiquiátricos: a de prover abrigo.

Desse modo, por um lado, temos iniciativas ligadas à moradia para clientela dos hospitais e, mesmo assim, apresentando evidentes dificuldades para atingir as metas requeridas. Por outro lado, não contamos ainda com políticas de Estado voltadas para garantir moradias adequadas ao crescente número de pacientes com TMG atendidos na ampla rede nacional de Caps.

Estudos nacionais têm enfatizado aspectos intrínsecos aos SRTs, traçando paralelos entre a vida no hospital e na nova moradia (Mângia, Ricci, 2011; Santos Jr. et al., 2009; Vidal, Bandeira, Gontijo, 2008; Cadernos IPUB, 2006), buscando compreender eventuais repercussões na subjetividade dos usuários (Pinheiro, Machado, 2011; Sztajnberg, Cavalcanti, 2010; Wachs et al., 2010; Suiyama, Rolim, Colvero, 2007) e o cotidiano nas casas (Amorin, Dimenstein, 2009), sendo mais raro o questionamento dos limites dos SRTs como resposta às necessidades de moradia (Furtado et al., 2013; Venturini, 2010).

Por isso, consideramos que o conhecimento das experiências, concepções e tipos de moradia efetivamente implementadas em outros países pode subsidiar discussão crucial para a reforma psiquiátrica brasileira: a necessidade de ampliarmos os modos de apoio à habitação de pessoas com TMG. A criação de um leque de possibilidades amplo, diverso e flexível o suficiente para garantir o direito a moradias socialmente inseridas à maior quantidade possível de pessoas é imperiosa para a contínua qualificação da reforma psiquiátrica em curso.

\section{Ampliar e diversificar: subsídios para a diversificação de moradias no Brasil}

Pretendemos contribuir para o debate sobre o tema no Brasil, estabelecendo novas perspectivas para duas grandes e distintas clientelas: 1) os moradores de SRTs, que contariam com um leque de novas possibilidades de moradia, à medida que eles próprios optassem por se mudar de seus SRTs; 2) usuários de Caps que, ainda que não possuam histórico de longos períodos de internação, mas necessitam de um local estável, seguro, privativo e confortável para morar.

Países como Canadá e EUA possuem diferentes modalidades de apoio do Estado a diversos tipos de moradia para pessoas com transtorno mental grave e que vêm sendo objeto de pesquisas e avaliações sistemáticas (Nelson, Aubry, Hutchison, 2010). Estudo envolvendo metanálise de várias pesquisas sobre moradias em meio comunitário (Leff et al., 2009) indica que respostas adequadas às necessidades de habitação da clientela aqui enfocada são fatores de proteção preponderantes no que tange a potenciais 
reinternações e suicídios, dentre outros fatores. No mesmo estudo, Leff et al. (2009) concluem que a existência de distintos modelos de moradia possibilita diferentes suportes para distintas clientelas, permitindo modelar e adequar o suporte aos diferentes moradores. Mercier (2004), revendo os últimos quarenta anos de políticas públicas voltadas a moradia para pessoas com transtorno mental grave na província de Quebec, no Canadá, identifica três características essenciais que se sucederam nesse período: inicialmente, nos anos 1960, moradias como alojamento, em resposta às necessidades de abrigo aos egressos de hospitais psiquiátricos; nos anos 1970 e 1980, ocorre associação entre a função de alojamento e serviços de reabilitação; e, a partir dos anos 1990, passa-se a conceber as moradias como um direito e meio de acesso à cidadania plena. Naturalmente, essas diferentes concepções redundaram em distintas iniciativas e variadas formas de combinar moradia e suporte por parte das redes de saúde mental locais. Ressalte-se, no entanto, que essa revisão feita por Mercier (2004), tomando como base a província de Quebec, não seria aplicável ao restante do Canadá (Fourchuck et al., 2007).

De maneira sintética, poderíamos afirmar que o modelo de habitação para pessoas com TMG, nesses dois países da América do Norte, poderia ser representado por um continuum, havendo, de um lado, moradias altamente estruturadas em termos de rotinas e pessoal de apoio; e, de outro, moradores com maior autonomia para estruturar suas rotinas e o próprio suporte que consideram necessário (Pelletier et al., 2009). Nesse sentido, em interessante trabalho, Nelson et al. (2010) distinguem as moradias em dois grandes grupos: aquelas nas quais seus moradores não contam com processo de reabilitação acoplado, e outras cujos moradores contam com diferentes suportes visando à sua reabilitação psicossocial e ganhos de autonomia (vide Quadro 1).

Quadro 1. Tipos de moradia segundo o suporte oferecido

\begin{tabular}{|c|l|l|l|}
\hline \multirow{2}{*}{ Sem reabilitação } & \multicolumn{2}{|c|}{$\begin{array}{c}\text { Família original } \\
\text { Pensões e abrigos públicos } \\
\text { Família de acolhimento } \\
\text { Vida na rua (homeless) }\end{array}$} \\
\hline \multirow{2}{*}{ Com reabilitação } & $\begin{array}{l}\text { Concepções distintas } \\
\text { Supervisionadas in loco } \\
\text { (supportive housing) }\end{array}$ & $\begin{array}{l}\text { Tipos de moradia } \\
\text { Lares abrigados, vilas, } \\
\text { apartamentos supervisionados }\end{array}$ & Diuturno, na própria casa \\
\cline { 2 - 4 } & $\begin{array}{l}\text { Com apoio comunitário } \\
\text { (supported housing) }\end{array}$ & Casas comuns na comunidade & $\begin{array}{l}\text { Modulado, segundo necessidades ou } \\
\text { demandas. Normalmente, fora de casa. }\end{array}$ \\
\hline
\end{tabular}

${ }^{2}$ A experiência brasileira de famílias de acolhimento restringe-se à assistência heterofamiliar de Juliano Moreira e Franco da Rocha, já citada.
Para os autores Nelson, Aubry, Hutchison (2010), o morar com a própria família de origem, as famílias de acolhimento e a vida na rua (homelessness) constituiriam um conjunto de moradias privadas de necessário e acoplado processo de reabilitação. As famílias de acolhimento (foster home em inglês, résidence d'accueil em francês) constituem experiência pioneira de alternativa de moradia a internos de hospitais psiquiátricos nos EUA e no Canadá, datando sua existência de mais de cinquenta anos atrás nesse último e persistindo até os dias atuais² (Piat, Sabetti, 2010).

As casas de acolhimento canadenses e americanas são normalmente estruturadas em torno de um casal que se dispõe a receber um ou vários egressos em sua residência, tornando-se cuidadores. Na maioria das vezes, os cuidadores são donas de casa que podem abrigar até nove residentes, mantendo contato estreito com a equipe do hospital de origem de seus pensionistas e/ou com o profissional de referência do serviço de saúde mental mais próximo. 
As expectativas colocadas sobre esses cuidadores em relação ao cotidiano - zelar pelo espaço físico, limpeza, saúde orgânica e alimentação dos moradores, promover contínua aquisição de autonomia mais aquelas de ordem institucional - integrar-se com as equipes de saúde mental - frequentemente entram em conflito com o fato de esses não necessariamente possuírem formação profissional específica e carecerem de mais treinamento (Piat, Sabetti, 2010). Por sua vez, os cuidadores dessas casas de acolhimento referem basear-se no bom senso e na ética da dignidade humana para desenvolverem seus trabalhos junto aos moradores, e queixam-se de sobrecarga, sobretudo por se verem responsáveis o tempo todo, sete dias por semana, pelo que acontece na casa.

Torna-se quase inevitável traçar paralelos entre a figura do cuidador nas famílias de acolhimento canadenses e os cuidadores de SRTs brasileiros. Em nossos trabalhos de campo, também identificamos um conjunto não necessariamente harmonioso de expectativas e atribuições relativas aos cuidadores: zelar pela limpeza e adequação do espaço físico, pelas roupas e pela alimentação e, ainda, estimular a contínua aquisição de autonomia pelos residentes, além de administrar conflitos inevitáveis. O que configura evidente sobrecarga, levando em conta tratar-se de pessoas em geral com baixa escolaridade, com fraca inserção nas equipes de saúde mental e recebendo pouco ou nenhum suporte das mesmas (Silva, Vaz, Campos, 2013; Cardoso et al., 2012), a despeito da importância de seu trabalho ressaltada por Sprioli e Costa (2011). Outra convergência é certo distanciamento, por parte dos trabalhadores dos Caps, das questões ligadas às moradias dos usuários, o que talvez seja reflexo de certa desconexão entre a política de desinstitucionalização brasileira e outras voltadas para moradias na comunidade, conforme identificado por Forchuk et al. (2007) em algumas províncias do Canadá.

Retomando a proposição de Nelson et al. (2010), temos que as famílias de acolhimento, juntamente com abrigos sociais, pensões e quartos em pequenos hotéis, constituiriam moradias típicas da primeira onda de desinstitucionalização na América do Norte, nos anos 1960, caracterizadas por restringir-se ao fornecimento de alimentação e casa limpa, atividades realizadas por trabalhadores não profissionalizados. Estes últimos enfocariam mais os déficits do que as potencialidades dos moradores, não enfatizando habilidades ou treinando sua independência. O somatório dessas situações traria importante impacto negativo à saúde mental e à qualidade de vida dos moradores (Nelson, Aubry, Hutchison, 2010). Tal carência de promoção de autonomia e restrito acompanhamento poderia ser explicada pelo fato de as chamadas "moradias sem reabilitação", citadas por Nelson, Aubry, Hutchison (2010), serem anteriores ao surgimento da concepção e das práticas de reabilitação psicossocial.

Moradias que contam com reabilitação psicossocial para os seus residentes surgirão apenas a partir dos anos 1970, combinando a ideia de lar com suportes diversos em direção à aquisição de autonomia, tudo isso em um mesmo lugar. As moradias com apoio (supportive housing) e as moradias com suporte na comunidade (supported housing) representariam, no plano operacional, o entrelaçamento entre moradia e reabilitação psicossocial. No entanto, esses dois modos de apoio e suporte apresentam significativas diferenças entre si, como veremos a seguir.

Moradias com apoio (supportive housing) caracterizam-se pela ideia de criar um ambiente na residência que permita e estimule aprendizagens diversas pelos residentes. Calcada na ideia de um continuum, a moradia com apoio objetiva a progressiva aquisição de habilidades pelos residentes, que, assim, irão mudar para outras casas, nas quais Ihes serão requeridas novas competências, até que se venha a atingir um nível ideal, no qual eles se tornem o mais independentes possível e apresentem menor necessidade dos serviços. Inspiradas fortemente em estratégias voltadas para pessoas com retardo mental (Morin, Robert, Dorvil, 2001), tais moradias apresentam-se sob a forma de lares abrigados, apartamentos supervisionados e "vilas" (grupos de casas), podendo o número de residentes variar de duas a 12 pessoas. Outra característica delas é o fato de os trabalhos de reabilitação serem desenvolvidos, em grande parte, no interior das residências.

Em contraste com o modelo anterior (supportive housing), as moradias com suporte na comunidade (supported housing) caracterizam-se por dissociar as funções de alojamento e moradia daquelas de suporte. O americano National Institute of Mental Health (NIMH) define suporte na comunidade (supported housing) como "uma abordagem focada no usuário e em seus objetivos e propósitos, usando processo de reabilitação individualizado e flexível, com forte ênfase na ideia de uma moradia comum, além de inserção no trabalho e constituição de rede social" (Fakhoury et al., 2002, p.309). O suporte é 
fornecido por serviços externos, frequentemente distintos das equipes que organizam as moradias. Nessa abordagem, a moradia é concebida como um lugar para os residentes viverem, não devendo ser utilizada como um setting terapêutico. Os apartamentos e casas são autônomos, não agrupados, e seus residentes recebem suporte segundo suas necessidades ou demandas. Dada sua plasticidade e flexibilidade, as moradias com suporte comunitário têm sido especialmente defendidas como alternativa a todos os modelos anteriores (Nelson, Aubry, Hutchison, 2010; Piat, Sabetti, 2010; Morin, Dorvil, 2001).

Nesse universo de possibilidades, faz sentido investigar as preferências dos residentes em relação às mesmas. Em amostra constituída por 315 usuários residentes em moradias com intensa supervisão, Piat et al. (2008) constataram que $44 \%$ dos entrevistados preferiam viver em seus próprios apartamentos sem suporte e $15 \%$ preferiam apartamentos supervisionados. Segundo a autora (Piat et al., 2008), os achados contrastam com as respostas dadas pelos trabalhadores. Quando se trata de apontar modalidades de moradia para seus clientes, $26 \%$ dos trabalhadores preferiram apartamentos supervisionados e mais da metade (52\%) apontou moradias tradicionais, como famílias de acolhimento. Esses números parecem indicar que os usuários preferem moradias mais autônomas em relação à rede de serviços e aos profissionais de saúde, enquanto esses últimos se mostram mais conservadores, preferindo abordagens graduais ao longo de uma rede de possibilidades de habitações.

\section{À guisa de conclusão}

Na pesquisa avaliativa desenvolvida sobre inserção social e habitação dessa clientela, notamos significativa diversidade nas condições e maneiras pelas quais usuários de Caps, considerados casos graves pelas equipes, não inseridos em SRTs, estabelecem suas moradas (Furtado, Nakamura, 2013). Nesse estudo qualitativo e multicêntrico, tivemos a oportunidade de acompanhar pessoas que moram na rua, assim como outras que permanecem alojadas em albergues religiosos com centenas de outros indivíduos, convergindo com estudos quantitativos sobre distúrbios mentais entre usuários de albergue realizados por Lovisi et al. (2002), no Rio de Janeiro. Pudemos acompanhar também usuários que, a partir dos benefícios a que têm direito e de renda proveniente de trabalhos informais, se casam ou estabelecem lares com os quais se dizem satisfeitos. Ou seja, no estudo citado (Furtado, Nakamura, 2013), evidenciamos significativas e diversificadas alternativas de os pacientes graves de Caps equacionarem suas necessidades de moradia.

No Brasil da atualidade, os SRTs se tornaram sinônimo de moradias para pessoas com TMG. O que traz dois problemas relevantes: um primeiro, de ordem quantitativa, é que essa visão deixa de fora de políticas de moradia boa parte da crescente clientela composta de usuários graves de Caps sem histórico de internações. O segundo, de ordem qualitativa, é a inexistência de outros tipos - e em maior quantidade - de moradias para distintas clientelas, contemplando suporte flexível e modulado às peculiaridades de cada usuário. Ampliar a clientela atendida, por meio da diversificação de opções e modos de acompanhamento, parece ser estratégia fundamental para o atual estágio da reforma psiquiátrica brasileira, superando os SRTs como único e exclusivo paradigma.

Não se podem negligenciar os modos como os milhares de usuários atendidos pelos 1.742 Caps existentes (Brasil, 2012) vêm equacionando suas necessidades de moradia, num contexto de inexistência de apoio sistemático e de políticas públicas destinados a essa questão. Estima-se que 30\% dos pacientes de Caps possam ser considerados casos graves, o que equivaleria a aproximadamente cento e vinte mil indivíduos, se tomarmos como base extenso trabalho realizado nos três estados do Sul do país por Pinho e Kantorski (2011). São números expressivos, requerendo iniciativas que podem ser decisivas se considerado o contexto de sensível retração de leitos hospitalares - redução de vinte mil leitos entre 2000 e 2011 - e de efetiva expansão do tratamento centrado na comunidade, de 208 Caps no ano 2000 para 1.742 Caps em 2011, conforme últimos números oficialmente divulgados pela Coordenação Nacional de Saúde Mental do Ministério da Saúde (Brasil, 2012).

A estruturação do espaço de habitação, privativo por excelência, requer plasticidade aos intentos de seus moradores e flexibilidade no suporte, de modo a garantir um acompanhamento na acepção primeira da palavra: o de ir atrás - no caso, atrás dos indícios levantados pelos usuários. O resgate 
histórico de algumas iniciativas de transposição de internos para a comunidade e a análise de tipologias existentes em outros países apontam possibilidades a serem exploradas ou resgatadas em solo nacional nesse sentido.

As experiências, nas últimas décadas, de moradias para pessoas com TMG parecem apontar para a necessidade de diversidade de opções. Os estudos mais recentes têm dado ênfase à separação entre o lar, lugar de morar, e os settings terapêuticos e demais locais para o desenvolvimento de reabilitação psicossocial. Tal separação é oriunda da nova perspectiva de constituição das moradias para pessoas com TMG como casas de cidadãos, equivalendo aos mesmos direitos dos demais cidadãos. Nesse caso, o suporte não deve ser estruturado a priori, e que o morador possa ter, como companheiros de morada, não necessariamente outras pessoas com transtornos mentais, mas outras pessoas que o mesmo considere, por algum motivo, significativas para ele.

\section{Agradecimento}

Esse texto é oriundo de pesquisa financiada pelo Cnpq por meio do edital 2008-4, processo n. 575150/2008.

\section{Referências}

AMARANTE, P. (Org.). Loucos pela vida: a trajetória da reforma psiquiátrica no Brasil. Rio de Janeiro: Ed. Fiocruz, 2001.

AMORIM, A.K.M.A.; DIMENSTEIN, M. Desinstitucionalização em saúde mental e práticas de cuidado no contexto do serviço residencial terapêutico. Cienc. Saude Colet., v.14, n.1, p.195-204, 2009.

BARROS, S.; BICHAFF, R. Desafios para a desinstitucionalização: censo psicossocial dos moradores em hospitais psiquiátricos do estado de São Paulo. São Paulo: Ed. Imprensa Oficial, 2008.

BEAULIEU, A.; DORVIL, H. L'habitation comme déterminant social de la santé mentale. Montreal: Ed. Acfas, 2004.

BRAGA-CAMPOS, F; GUARIDO, E. Sentir-se em casa no olho da rua: o desafio das moradias. Cad. IPUB, v.12, n.22, p.141-8, 2006.

BRASIL. Ministério da Saúde, Secretaria de Atenção à Saúde, Coordenação Geral de Saúde Mental. Saúde Mental em Dados. Brasília: MS, 2012. n.10.

Ministério da Saúde. Secretaria Executiva. Legislação em saúde mental: 1990-2002. Brasília: MS, 2002.

. Ministério do Trabalho e Assistência Social. Secretaria de Assistência Médica. Manual de serviço para assistência psiquiátrica. Orientação de serviço n. 3043. Brasília: Ministério do Trabalho e Assistência Social, 1973.

CADERNOS IPUB. Desinstitucionalização: a experiência dos serviços residenciais terapêuticos. Cad. IPUB, v.12, n.22, p.1-244, 2006.

CARDOSO, L. et al. Perspectivas atuais sobre a sobrecarga do cuidador em saúde mental. Rev. Esc. Enferm. USP, v. 46, n.2, p.513-17, 2012.

CORDEIRO, A.M. et al. Revisão sistemática: uma revisão narrativa. Rev. Col. Bras. Cir., v.34, n.6, p.428-31, 2007.

COUTO, M. Venenos de Deus, remédios do diabo. São Paulo: Companhia das Letras, 2012. 
DORVIL, H. L'habitation et la santé mental. In: DORVIL, H.; BEAULIEU, A. (Orgs.). L'habitation comme déterminant social de la santé mentale. Laval: Acfas, 2004. p.3-12.

FAKHOURY, W.K.H. et al. Research in supported housing. Soc. Psychiatr. Epidemiol., v.37, n.5, p.301-15, 2002.

FOURCHUK, C. et al. Housing, income support and mental health: points of disconnection. Health Res. Policy Syst., v.5, 2007. Available from: <http:// www.ncbi.nlm.nih.gov/pmc/articles/PMC2238740/?tool=pubmed>. Access: 15 jun. 2010.

FURTADO, J.P. Avaliação da situação atual dos Serviços Residenciais Terapêuticos no SUS. Cienc. Saude Colet., v.11, n.3, p.785-95, 2006.

FURTADO, J.P.; NAKAMURA, E. (Orgs.). Inserção social e habitação de pessoas com sofrimento mental grave: um estudo avaliativo. São Paulo: Ed. Unifesp, 2013.

FURTADO, J.P.; PACHECO, R.A. Moradias extra-hospitalares para pacientes psiquiátricos em Campinas: análise de uma experiência. J. Bras. Psiquiatr., v.47, n.4, p.179-84, 1998

FURTADO, J.P. et al. Modos de morar de pessoas com transtorno mental grave no Brasil: uma avaliação interdisciplinar. Cienc. Saude Colet., no prelo, 2013.

GOLDSTEIN, J.L.; GODEMONT, J.M.L. The legend and lessons of Geel, Belgium: a 1500 -year-old legend, a $21^{\text {st }}$. century model. Community Ment. Health J., v.39, n.5, p.441-58, 2003.

GUIMARÃES, J.; SAEKI, T. Janelas do Santa Tereza: estudo do processo de reabilitação psicossocial do hospital psiquiátrico de Ribeirão Preto (SP). Hist. Cienc. Saude Manguinhos, v.8, n.2, p.357-74, 2001.

LEDUC, A. Histoire du traitement familial à Geel. Santé Mentale Québec, v.12, n.1, p.156-61, 1987.

LEFF, H.S. et al. Does one size fit all? What we can and can't learn from a metaanalysis of housing models for persons with mental illness. Psychiatr. Serv., v.4, n.60, p.473-82, 2009.

LOVISI, G.M. et al. Social disablement among residents of hostels for the homeless in Rio de Janeiro, Brazil. Int. J. Soc. Psychiatry, v.48, n.4, p.279-89, 2002.

MÂNGIA, E.F.; RICCI, E.C. Pensando o habitar trajetórias de usuários de serviços residenciais terapêuticos. Rev. Ter. Ocup., v.22, n.2, p.182-90, 2011.

MERCIER, C. L'Évolution des liens entre le logement et l'insertion sociale à travers 40 ans de documents ministériels au Québec. In: BEAULIEU, A.; DORVIL, H. (Orgs.). L'habitation comme détermiant social de la santé mentale. Montreal: Ed. Acfas, 2004. p.19-26.

MOREIRA, J. Ligeiras notas a propósito da assistência familiar. Arch. Bras. Psychiatr. Neurol. Scienc. Afins, v.2, n.1, p.25-29, 1906.

MORIN, P.; DORVIL, H. Dossier: le logement social et I'hebergement. Quebec: Université du Québec, 2001.

MORIN, P.; ROBERT, D.; DORVIL, H. Le logement comme facteur d'intégration sociale pour les personnes classes maladies mentales et les personnes classes déficientes intellectuelles. Montreal: Université de Montréal, 2001.

NELSON, G.; AUBRY, T.; HUTCHISON, J. Housing and Mental Health. In: STONE, J.H.; 
BLOUIN, M. (Eds.). International Encyclopedia of Rehabilitation. 2010. Available from: <http://cirrie.buffalo.edu/encyclopedia/article.php?id=132\&language $=$ en $>$. Access: 30 ago. 2011.

ODA, A.M.G.R. História das primeiras instituições para alienados no Brasil. Hist. Cienc. Saude - Manguinhos, v.12, n.3, p.983-1010, 2005.

PALLADINI, P.C.N. Dois anos e meio de Lar Abrigado no Juqueri. Arq. Saude Ment. Est. São Paulo, v.7, n.46, p.62-66, 1986-1987.

PELLETIER, J-F. et al. (Orgs.). Hébergement, logement et rétablissement en santé mentale. Quebec: Presses Universitaires du Quebec, 2009.

PEREIRA, M.G. Artigos científicos - como redigir, publicar e avaliar. Rio de Janeiro: Guanabara-Koogan, 2011.

PIAT, M.; SABETTI, J. Residential housing for persons with serious mental illness: the fifty year experience with foster homes in Canada. In: STONE, J.H.; BLOUIN, M. (Eds.). International Encyclopedia of Rehabilitation. 2010. Available from: <http:// cirrie.buffalo.edu/encyclopedia/article.php?id=236\&language=en>. Access: 30 ago. 2011.

PIAT, M. et al. Housing for persons with serious mental illness: consumer and service provider perspectives. Psychiatr. Ser., v.59, n.9, p.1011-7, 2008.

PINHEIRO, J.A.C.; MACHADO, L.D. Experiência clínica por meio de imagens cartográficas. Psicol. Soc., v.23, n.esp., p.120-8, 2011.

PINHO, L.B.; KANTORSKI, L.P. Psychiatric care in the Brazilian context. Cienc. Saude Colet., v.16, n.4, p.2107-14, 2011.

SANTOS JUNIOR, H.P.O.; SILVEIRA, M.F.A. Práticas de cuidados produzidas no serviço de residências terapêuticas: percorrendo os trilhos de retorno à sociedade. Rev. Esc. Enferm. USP, v.43, n.4, p.788-95, 2009.

SARACENO, B.A. Libertando identidades: da reabilitação psicossocial à cidadania possível. Rio de Janeiro: TeCorá, 1999.

SILVA, E.A.; VAZ, B.C.; CAMPOS, F.C.B. Cuidadores e convívio: em cena as relações nos serviços residenciais terapêuticos. In : FURTADO, J.P.; NAKAMURA, E. (Orgs.). De muitas maneiras: inserção social e habitação de pessoas com sofrimento mental grave no Brasil. São Paulo: Ed. Unifesp, 2013. [No prelo].

SPRIOLI, N.; COSTA, M.C.S. Cuidar em novo tempo: o trabalho de cuidadores com pacientes psiquiátricos em moradias. Rev. Latino-Am. Enferm., v.19, n.5, p.1155-62, 2011.

SUIYAMA, R.C.B.; ROLIM, M.A.; COLVERO, L.A. Serviços residenciais terapêuticos em saúde mental: uma proposta que busca resgatar a subjetividade dos sujeitos? Saude Soc., v.16, n.3, p.102-10, 2007.

SZTAJNBERG, T.K.; CAVALCANTI, M.T. A arte de morar... na Lua: a construção de um novo espaço de morar frente à mudança do dispositivo asilar para o Serviço Residencial Terapêutico.. Rev. Latinoam. Psicopatol. Fundam., v.13, n.3, p.457-68, 2010.

TRIEMAN, N.; LEFF, J.; GLOVER, G. Outcome of long stay psychiatric patients resettled in the community: prospective cohort study. Brit. Med. J., v.319, n.6, p.13-6, 1999.

TSEMBERIS, S. L'intégration sociale des patients psychiatriques désinstitutionnalisés: I'expérience de New York. In: BEAULIEU, A.; DORVIL, H. (Orgs.). L'habitation comme déterminant social de la santé mentale. Montreal: Acfas, 2004. p.55-62. 
URQUIZA, L.M.F.P. Um tratamento para a loucura: contribuição à história da emergência da prática psiquiátrica no estado de São Paulo. 1991. Dissertação (Mestrado) - Departamento de Psiquiatria e Psicologia Médica, Universidade Estadual de Campinas, Campinas. 1991.

VENANCIO, A.T.A. Da colônia agrícola ao hospital-colônia: configurações para a assistência psiquiátrica no Brasil na primeira metade do século XX. Hist. Cienc. Saude - Manguinhos, v.18, supl.1, p.35-52, 2011.

VENTURINI, E. O caminho dos cantos: morar e intersetorialidade na saúde mental. Fractal Rev. Psicol., v. 22, n.3, p.471-9, 2010.

VIDAL, C.E.L.; BANDEIRA, M.; GONTIJO, E.D. Reforma psiquiátrica e serviços residenciais terapêuticos. J. Bras. Psiquiatr., v.57, n.1, p.70-9, 2008.

WACHS, F. et al. Processos de subjetivação e território de vida. Physis, v.2, n.3, p.895-912, 2010.

FURTADO, J.P. Subsidios para la diversificación de la vivienda para las personas con trastorno mental grave en Brasil: una revisión. Interface (Botucatu), v.17, n.46, p.635-47, jul./set. 2013

Con las críticas al denominado manicomio, en diversos países fue necesario implementar diversas iniciativas de vivienda para egresados de hospitales psiquiátricos. En este artículo, a partir de la revisión narrativa, analizamos los antecedentes y la constitución de viviendas para personas con trastorno mental grave implementadas en Brasil, por el Sistema Único de Salud Brasileño (SUS). Identificamos poca discusión sobre los límites del Programa de Servicios Residenciales Terapéuticos (SRTs) y la casi inexistencia de discusiones sobre alternativas para las necesidades de vivienda de pacientes graves vinculados a los Centros de Atención Psicosocial (CAPS). Con base en reflexiones provenientes de la experiencia canadiense, discutimos la necesidad y los posibles caminos de ampliación, no solo cuantitativa, mas principalmente cualitativa, de las formas de apoyo a las viviendas de personas con trastorno mental grave en Brasil.

Palabras clave: Salud Pública. Evaluación de programas y proyectos de salud. Salud mental. Instituciones de vida asistida. 
